\title{
The Girl in the Book: a screenplay on child abuse, personality dysfunction and recovery - of interest to not only psychiatry
}

\section{Geoffrey Windle \& K. Martin Beckmann}

The Girl in the Book is a screenplay of interest to mental health professionals. It is a 2015 cinematic achievement written and directed by Marya Cohn. It stands at par with 'One Flew Over the Cuckoo's Nest' by Milos Foreman, 'Rainman' by Barry Levinson, and 'As Good As It Gets', directed by James L. Brooks - educational about electroconvulsive therapy (ECT), Asperger syndrome, obsessivecompulsive disorder (OCD). The Girl in the Book may easily facilitate a discussion about the following:

1. At what stage of impairment does a person qualify for a diagnosis of personality disorder?

2. What severity of abuse qualifies as childhood abuse?

3. What does recovery look like in the absence of engaging with mental health services, either private or public?

Whilst the movie does not in itself provide frank answers to those questions, it has potential for psychiatrists, allied mental health practitioners and students alike: to facilitate learning through discussion.

It portrays part of the life story of Alice (Emily Van Camp), linking her early teens with her late twenties. Alice works as a book editor. Themes are her keen love of poetry and prose as a teenager, then the emotional dysregulation and impulsivity she experiences in her later teens and then her twenties. She deceives friends and loses friendships, making and breaking relationships with family and lovers alike. She does not access formal therapy. We suggest this is an example of resilience in the face of trauma. Interestingly there is no verbal abuse, no witnessing of domestic violence, there is no explicit emotional abuse, nor is there neglect as such, there is no physical abuse, and there is no non-consensual child sexual abuse. Alice experiences flashbacks from her childhood: a friend of her father, a famous writer Milan Daneker (Michael Nyqvist) grooms her. We learn that the perpetrator stole her personal and intimate reflections from her diary, shy records of her budding 
adolescence and developing womanhood. He seduces her and is her first lover at the age of 14 . The inflicted trauma is compounded in a scene where Alice tries to address this injustice by informing her parents of her intimate relationship with Milan but is not believed. Her cry for help comes off the back of Milan's wild success publishing a book on teenage experiences of puberty, which plagiarises her secrets, and for which Milan solely claims all the credit. Furthermore, we see just how important the father's working relationship with Milan is, and how this denigrates the necessary respect for the daughter and belief in her confiding. Alice finds this lack of faith on the part of her own guardian deeply hurtful. The movie ends with soft recovery for Alice - she testifies to her internal locus of control and deals constructively with her distress and past trauma by beginning to write her own novel: The Girl in the Book. 